\title{
Purposes, Politicisation and Pitfalls of Diplomatic Gift-giving to the United Nations
}

\author{
Loraine Sievers | ORCID: 0000-0003-3427-5128 \\ SCProcedure, Weston, CT, United States \\ lcsievers@earthlink.net
}

Received: 10 October 2020; revised: 25 November 2020; accepted: 17 January 2021

\section{Summary}

Politicisation has characterised diplomatic gift-giving to the United Nations since its early years. Donations of decor and furnishings in some instances can be an equaliser, and in others can accentuate inequalities. Member States' motives range from altruistic to self-seeking, but larger purposes are served, including increased cross-cultural understanding and community building.

\section{Keywords}

United Nations art collection - diplomatic gift-giving - cultural diplomacy

\section{Introduction}

On 7 October 1974, the Deputy Foreign Minister of the People's Republic of China stood beside Secretary-General Kurt Waldheim in the UN Delegates Lounge. Chiao Kuan-hua was there to present what the New York Times called 'a spectacular tapestry' of the Great Wall. Ten meters long and weighing 280 kilograms, its sheer size and vibrant colours awed the assembled diplomats, UN officials and reporters.

However, at the United Nations, rarely is a diplomatic gift merely a gift. Chiao affirmed that this donation from his country, which three years before had assumed China's seat at the UN, reflected 'the new outlook and new style 
of the new China:. ${ }^{1}$ It was seen in a similar light by a European diplomat, who remarked: 'To me its message is simple. It says China has arrived here and means to stay here. And it means China will have a prominent position in everything happening here from now on:'2

The rising political profile of the People's Republic of China was symbolised not only by its presentation of such a dramatic gift but also by the concurrent fate of another gift. Just prior to the arrival of the tapestry, a green marble plaque bearing a quotation by Confucius quietly disappeared from the entrance to that same lounge. The plaque, donated by the now ejected Republic of China, had been removed at the insistence of Beijing.

The intertwined stories of these two art objects exemplify the politicisation which characterises diplomatic gift-giving to the United Nations, and which dates back to before completion of the UN building in $1952 .^{3}$

In 1946, the General Assembly accepted a US invitation to locate the organisation's Headquarters in the United States. Immediately, the UN was inundated with unsolicited offers of decor and furnishings from governments, ${ }^{4}$ artists and philanthropists. The UN's team of architects initially held these offers in abeyance, for fear the building would become cluttered with works of dubious quality. However, their hand was eventually forced by a budget shortfall so severe that for the building plan to be approved, five floors had to be lopped off the tall Secretariat building. ${ }^{5}$

Thus unable to commission the necessary decor and furnishings, the UN had no choice but to proceed via donations. This placed the organisation's Secretary-General, Trygve Lie of Norway, and the architectural team in the

1 In 1971, the General Assembly, by Resolution 2758 (xxvI), recognized the representatives of the People's Republic of China as 'the only legitimate representatives of China to the United Nations' and simultaneously expelled the representatives of the Republic of China.

2 Teltsch 1974.

3 Although the many international organisations belonging to the UN system have also received significant art donations, this article focusses on UN Headquarters. It also focusses on Member States as donors, although there have been important gifts from civil society.

4 This was especially noteworthy because many of these offers came from countries which were still struggling with war-damaged economies.

5 UN Press Feature No. 213/Rev. 8 1974, 3. 
sensitive position of discouraging some offers, while trying to elicit others. It also gave additional weight to the wishes and tastes of prospective donors.

Politics quickly intruded. An initial priority was to furnish the principal meeting rooms. Without consulting the lead architect, Wallace K. Harrison, Lie unilaterally accepted offers from Denmark, Norway and Sweden to donate, respectively, the chambers of the Trusteeship, Security and Economic and Social Councils. Although the architectural and decorative styles of the Scandinavian countries were widely respected, the lack of consultation spurred the hasty creation of a Board of Art Advisers from France, Mexico, the United Kingdom and the United States. ${ }^{6}$

Jostling for control arose with respect to the Security Council Chamber in particular. Lie felt strongly that the chamber should correspond to the Council's sober mandate. It is widely believed that for that reason, he steered its design towards his own country, with which he would have greatest influence. ${ }^{7}$ The new Board, however, tried to exercise a modicum of decisionmaking power. Six months after Per Krohg, the artist designated by Norway, had begun a large painting for the chamber, the Board decided there should be no murals in the three chambers. In response, the Norwegian architect Anstein Arneberg declared that without Krohg's painting, he would walk off the job. ${ }^{8}$ This brinkmanship was followed by a royal decree from Norway, making its funding of the chamber conditional on the painting. ${ }^{9}$ Ultimately, Lie intervened to organise a visit to Krohg's studio in Oslo, after which the Board backed down. ${ }^{10}$

The other structural donations to the UN building proceeded largely without controversy. In addition to the other two council chambers, these included Canada's decorative bronze doors leading into the building from the Visitors Plaza and the carved wood panels of Conference Room 8, gifted by the United Kingdom. Early donations to the interior decor were the Belgian tapestry overhanging the Delegates Lobby, the Léger-designed murals on either side of the General Assembly Hall and the Netherlands' Foucault pendulum.

The fact, however, that so many of the significant initial gifts were from Western countries created a problem of a different order. In conjunction with the design of Headquarters as a skyscraper - an architectural form then

\footnotetext{
$6 \quad$ Louchheim 1951a.

$7 \quad$ Holme 2018, 86, 188.

8 Holme 2018, 115 .

$9 \quad$ Sandvik 2014, $15^{8}$.

10 Holme 2018, 120-121.
} 
quintessential to the United States - this risked sending out an unintended signal that the principal design elements of the home of the new 'world' organisation were in fact being largely defined by Western culture.

Fortunately, initial donors from other regions were not entirely absent. Countries of Latin America - a region accounting for 20 of the original 50 Charter signatories - provided two major gifts: a striking pair of floor-toceiling murals entitled War and Peace by Brazil's Candido Portinari, and a priceless 3,00o-year-old Peruvian burial mantle. Donations from Eastern Europe included large sculptures displayed in the UN Garden from the Soviet Union and Yugoslavia. In addition, a model of the first Soviet Sputnik satellite was suspended in the Public Lobby. ${ }^{11}$

Initially, there were relatively few gifts from Africa and Asia-Pacific. This reflected the fact that the Headquarters was being established prior to the first great wave of decolonisation, at a time when the UN had only four African and fourteen Asia-Pacific Member States. ${ }^{12}$ However, despite their donations originally being few in number, countries of the two regions presented some of the finest pieces in the UN art collection, among them a 70о вC statue of Osiris from Egypt, a 3rd-century mosaic from Tunisia, a Kente cloth from Ghana and the Indonesian Lounge with its Balinese statues of Peace and Prosperity.

Gifts to the United Nations continue to this day. A number of later donations have been of smaller size, which is advantageous since the obvious locations for large-scale objects have mostly been filled. Nonetheless, place is still occasionally found - both in outdoor spaces and along interior corridors - for bigger pieces. Among these are Finland's four-and-a-half-meter-tall stainless steel sculpture celebrating its composer Jean Sibelius, mounted on the Visitors Plaza, and Oman's massive, carved wood case containing ornate handicrafts, installed outside the Economic and Social Council Chamber.

11 This gift might have been provocative had it occurred in 1957, the year Sputnik 1 was launched, an event which appeared to give the Soviet Union a considerable edge over the United States in space technology. However, the year 1959, when the model was donated to the UN, marked a thaw, albeit brief, in superpower tensions. By then, the US government had sufficient confidence in its own space prowess such that when each country exchanged goodwill exhibits, the Soviet exhibit which travelled to several US cities was permitted to display models of all three of the first Sputniks. USSR Exhibition: New York 1959, 3. In 1970, 'outer space parity' in UN gift-giving by the two superpowers was achieved when the United States donated a moon rock, brought back by the Apollo 11 astronauts, which was also displayed in the Public Lobby. In contrast, today the two regional groups comprise 54 and 55 states, respectively. 
The UN art collection is so eclectic that it is sometimes wondered whether there are any standards at all. There are. But in their successive versions, the UN guidelines have been so broad, and so flexibly applied, that rarely has a proposed donation been rejected.

Initially, the UN Board of Art Advisers set out as core principles that Headquarters should not become a museum or exhibit hall, but that the art displayed there 'should be an accompaniment rather than a distraction, a background, not the center of interest'. It also affirmed that choices need not 'be limited to professional and deliberate painting; folk arts will be welcomed and the arts of the past, too'. It was understood that art for the 'great building on which the eyes of the world are fixed' should have aesthetic worth and be consonant with the UN's principles and purposes. ${ }^{13}$

Similar principles have been followed by later art advisers, including the high UN officials Brian Urquhart and Alvaro de Soto. In Urquhart's view, the art at the UN has become 'a surprisingly interesting and distinguished collection'. ${ }^{14}$ At the same time, he has stated that would-be donations were 'sometimes entirely unsuitable'15 and were declined, although the UN tried 'not to insult governments.' ${ }^{16}$ Rejection, however, is an extreme step. More often, questionable works of art have been accepted and then placed in obscure locations or in storage.

Politically, it can be difficult for the organisation to turn away gifts offered by states which play larger roles at the UN, including as major financial contributors. This mirrors a dilemma which can confront the UN when, for example, pressure is brought to bear on it to appoint specific nationals to high-level positions. Preferential treatment was given in one instance to the Soviet Union but for good cause. For some years the UN had declared a moratorium on accepting new gifts. Then, in 1990, a Soviet sculptor won the support of both Soviet President Mikhail Gorbachev and US Secretary of State James Baker for a statue of Saint George slaying a dragon sculpted from sections of genuine missiles from both countries. Given the importance to the UN of greater cooperation between these two countries, the sculpture was accepted, with de Soto hedging on the ban by saying, it 'is being relaxed very slowly'17

\footnotetext{
13 Louchheim 1951a.

14 Marks 1999, 10.

15 Urquhart 1987, 112.

16 Blair 1983.

17 Lewis 1990.
} 
The goals of donor states can be considered as fourfold: 1) to add to their stature at the UN; 2 ) to have on display visible representation of their national culture; 3) to symbolise their investment in the organisation's mission and 4) to contribute to enhancing the aesthetics of the UN premises. Former Secretary-General Boutros Boutros-Ghali commented that 'each gift represents the desire of a Member State to offer a part of itself, and of its aspirations for the future.'18 A fifth goal, posited by one commentator, is that governments 'try to score subtle political points through their gifts.' ${ }^{19}$ This can be through the donation itself but also through what is said at its dedication.

While donors' motives may range from altruistic to self-seeking, no government is likely to think that a single gift will enhance the way that its delegation is regarded at the UN. Rather, a well-chosen gift is more apt to be part of an overall strategy of using 'soft power' ${ }^{20}$ across a range of cultural activities for raising a state's profile - activities which can include hosting receptions, musical or theatrical events, tastings of national cuisine and exhibits on themes of national significance.

\section{Differences in Cultural Outlooks}

Member States' gifts sometimes reveal cultural and political profiles which may not otherwise be apparent in the day-to-day work of the organisation, where homogenisation is increasing as mother tongues cede place to English, and national dress to Western clothing. For diplomats not familiar with each other's cultures, donated works of art can stimulate interest and create greater cultural understanding. Many diplomats in New York are quick to volunteer that they have a favourite art piece, and often this appreciation is cross-cultural. For example, a Bulgarian diplomat has mentioned fondness for Nigeria's Anyanwu statue, while a British diplomat has praised the Portinari murals given by Brazil. ${ }^{21}$

Nonetheless, there is also the risk of creating offense cross-culturally through art. In their 2017 study of cultural diplomacy at the UN Office in Geneva, Melissa Nisbett and James Doeser affirm that 'one person's masterpiece can

\footnotetext{
18 Marks 1999, 9.

19 Winfield 20oo.

20 Nisbett and Doeser 2017, 16, note that whereas academics commonly make a distinction between 'soft power' and 'cultural diplomacy', diplomats tend to use these terms interchangeably 'without precision and in a very fluid manner'.

21 Bulgarian diplomat and British diplomat, conversations with the author, 2020. Empirically, it would appear that at the UN, appreciation of a particular art object is rarely dependent on the identity of the donor country.
} 
be another's blasphemy'.22 The nude statue of Zeus in the Public Lobby from Greece and the nearly nude figure of the 'Swords into Ploughshares' sculpture in the Garden from the Soviet Union, as well as the partially clothed women and men in the Belgian tapestry, would, for example, be shunned as subjects for public art in a number of countries.

Yet tolerance has generally been shown for a wide range of art subjects at the UN. Even art of a particular religion has not been deemed inappropriate. The Christian Khatchkar cross-stone monument from Armenia, an embroidered black silk curtain from Mecca and a carved stone excavated from a 4thcentury synagogue in Israel have all taken their places in the UN collection without objection.

As for the aesthetic dimension, varying degrees of quality and taste have generally been accepted within the UN community. It is understood that in contrast to bilateral gift-giving, where there is only one recipient in mind, giftgiving to today's UN involves the art orientations of 193 states, not all of which can possibly be pleased to the same degree.

However, more formal or sophisticated style preferences can sometimes clash with modernistic or casual tastes. As part of the Capital Master Plan renovations completed in 2014, the Netherlands undertook to re-envisage the furnishings of the Delegates Lounge. While praise for the introduction of 'Dutch Design' elements was widespread among outside design specialists, within the UN it was considered an 'epic fail'. Habitués wistfully contrasted the former leather, steel and glass furniture ${ }^{23}$ with the new tables and chairs of moulded plastic in white and bright green, which some likened to 'Ikea', or 'a terrible airport lounge..24 Fortunately, the Dutch delegation was sufficiently well liked to weather the storm.

The wish of donors to present to the UN art which promotes higher perspectives and values has sometimes put the organisation's collection ahead of national attitudes. Krohg depicted 'black and white prisoners of war, who are brothers in both degradation and liberation'25 at a time when racial inequality was deeply institutionalised in a number of Member States. And the portrayals of the horrors and destruction of war in UN art have been in advance of national statuary and paintings which depict the glory of military victories.

A side benefit to gifts given to the organisation is that shared ' $U N$ folklore' about them contributes to bonding. For example, Yugoslavia's statue of Peace,

\footnotetext{
22 Nisbett and Doeser 2017, 20.

23 These included Knoll club chairs and copies of Mies van der Rohe's Barcelona Chair. Betsky 2005, 71.

24 See, for example, Malone 2014.

25 Louchheim 1951b.
} 
depicted as a woman on horseback, dominates the view over the UN Garden from the Visitors Plaza. For decades, the UN community has smiled at the idea that Peace is riding not towards the UN but away from it. Such stories involving the UN collection (of which there are many), when recounted to new arrivals, can create a sense of belonging and of becoming an insider.

\section{5}

\section{Conclusions}

In addition to first-time donors, some states which, in earlier decades, gave gifts to the organisation have made further donations in later years, indicating the ongoing relevance to UN members of this form of visual diplomacy. ${ }^{26}$ As pointed out by Costas M. Constantinou: 'The visual plays a crucial role in diplomacy' and has traditionally 'figured as part of the dignified milieu or the ceremonial trappings of power that support the linguistic environment of diplomacy'.27 Specific to the UN context, Constantinou has written that official diplomatic gifts 'supposedly reflect on the brand image of both the organisation and the member state, amplifying the principles that guide their action.' ${ }^{28}$

Nonetheless, Iver B. Neumann cautions that there is 'no guarantee that fielding something that is expected to be visually effective will actually prove effective, for the simple reason that exactly what is visually pleasing varies so widely from polity to polity'. He adds that the visual is therefore 'a precarious modality in diplomacy'.29

Viewed objectively, diplomatic gift-giving to the UN may appear to be non-reciprocal, in that the donor does not receive a tangible gift of equivalent value from the organisation. Yet it is clear that a significant majority of states have concluded that worthwhile benefits nonetheless accrue from this practice. Evidence of this is found in the statistic that more than 140 of the UN's 193 Member States have given at least one gift. However, the fact that approximately 50 countries have not done so suggests that gift-giving to the $\mathrm{UN}$ is regarded by the diplomatic community as optional, and not essential to developing a respected profile at the organisation.

Within the broad range of cultural activities carried out by Member States, it is virtually impossible to isolate the impact of a particular gift. Nonetheless, decor and furnishings given to the UN may have a longer-lasting effect than

26 For example, in 1995, two decades after donating the Great Wall tapestry, China gave the UN the large bronze Centenary Tripod, another object having important national significance.

27 Constantinou 2018, 104.

28 Constantinou 2021.

29 Neumann 2020, 56-57. 
an expensive reception or concert which, once over, may soon be forgotten. Norway's donation of the Security Council Chamber, and its later renovation, have been sources of enduring prestige. These were highlighted as part of Norway's campaign for a 2021-2022 seat on the Council, and in fact Norway's campaign logo was the stylised heart of the chamber's decorative fabric.

In some instances, gift-giving to the UN can be an equaliser. A small state may donate a relatively inexpensive handicraft which, because of its uniqueness and workmanship, may gain more positive attention than another state's costlier gift. One fairly modest donation which is widely appreciated comes from the island of Palau (population 17,900). It is a 1.5-meter wooden eel which narrates a story through intricate carvings on both sides and has been deemed worthy of display in the high-traffic area outside the Trusteeship Council.

In other instances, gift-giving can accentuate inequalities. The Capital Master Plan renovations created opportunities for redecorating the Delegates Lounge, the Security Council Consultations Room and an adjacent area, but these projects fell well outside the reach of smaller states and rather were financed, respectively, by the Netherlands, the Russian Federation and Turkey.

Overall, it would be too narrow to conclude that states evaluate their own, and others', gifts to the UN solely on the basis of direct national gain. Each gift to the organisation adds to the collective backdrop of the daily formal and informal conversations which take place there. As Michael Adlerstein, chief architect of the Capital Master Plan, has observed: 'The delegates enjoy the collection. It is their art, and it is their house'. ${ }^{30}$

\section{Bibliography}

Adlerstein, Michael. 'We Are Not a Museum'. Vereinte Nationen: German Review of the United Nations 62 (4) (2014), 152-155.

Betsky, Aaron. The U.N. Building (London: Thames and Hudson, 2005).

Blair, William G. 'U.N. Art Collection, like the U.N., Keeps Growing'. The New York Times, 13 March 1983, sec. 1, $5^{2}$.

Constantinou, Costas M. 'Diplomacy'. In Visual Global Politics, ed. Roland Bleiker (Abingdon: Routledge, 2018), 104-110.

Constantinou, Costas M. 'Around the Broken Chair: Locationality, Visuality and the Vibrancy of Diplomatic Objects'. The Hague Journal of Diplomacy 16 (1) (2021), this issue.

Holme, Jørn, ed. The Security Council Chamber (Oslo: Forlaget Press, 2018). 
Lewis, Paul. 'How St. George Ended up at the U.N'. The New York Times, 30 September 1990, sec. 1, 17 .

Louchheim, Aline B. 'Art for United Nations'. The New York Times, 17 June 1951a, sec. X, 6. Louchheim, Aline B. 'A UN Art Problem'. The New York Times, 28 December 1951b, sec. X, 12.

Malone, Noreen. 'Undercover at the U.N. Lounge, Where Diplomats Get Drunk and Handsy'. The New Republic, 30 January 2014. https://newrepublic.com/article/116239/ united-nations-lounge-drinking-diplomats.

Marks, Edward B. A World of Art: The United Nations Collection (Rome: Il Cigno Galileo Galilei, 1999).

Neumann, Iver B. Diplomatic Tenses: A Social Evolutionary Perspective on Diplomacy (Manchester: Manchester University Press, 2020).

Nisbett, Melissa and James Doeser. The Art of Soft Power: A Study of Cultural Diplomacy at the UN Office in Geneva (London: King's College, 2017).

Sandvik, Maria Veie. 'Per Krohg's Painting in the United Nations Security Council'. Vereinte Nationen: German Review of the United Nations 62 (4) (2014), 156-162.

Teltsch, Kathleen. 'U.N. Is Given 2 Chinese Works of Art'. The New York Times, 8 October 1974, 86.

UN Press Feature No. 213/Rev. 8 (New York: UN, 28 February 1974).

Urquhart, Brian. A Life in Peace and War (New York: Harper and Row, 1987).

USSR Exhibition: New York. Moscow, H-136-11, n.p. (1959), pamphlet.

Winfield, Nicole. 'UN Collection Blends Art with Politics and Diplomacy'. Associated Press, 3 January 2000.

\section{Loraine Sievers}

co-authored the fourth edition of The Procedure of the UN Security Council (Oxford University Press, 2014) and is the Director of the SCProcedure website (http://www.scprocedure.org), which analyses new Security Council procedural developments as they occur. She served as a full-time United Nations staff member for over 30 years, concluding her career as Chief of the Security Council Secretariat Branch. In that position, among her responsibilities were providing guidance to Council members, especially each month's rotating Council President, on the Council's working methods; assisting the Council's Informal Working Group on documents and procedure; and serving as liaison between the Council members and the architectural team managing the Capital Master Plan renovations of the UN premises. Previously, she served as Secretary to the Afghanistan and Sierra Leone Sanctions Committees, as a political analyst in the Regional Affairs Division, and as a departmental speechwriter. She contributed to the organisation's Blue Book series on crises addressed by the UN, the Repertoire of the Practice of the Security Council and the Secretary-General's Press Analysis. 